\title{
Critical Thinking in Midwifery Practice: A Conceptual Model Introduction
}

This paper presents a culmination of doctoral work that resulted in the development of a conceptual model of critical thinking in midwifery practice. The model was developed from a program of research undertaken as part of the first author's doctoral program, the results of which were presented as a series of published papers. This paper describes the elements and concepts of the model and refers to the previous published work to demonstrate how the conceptual model was developed and created. This new model provides a framework to guide curriculum design and teaching strategies to promote this important cognitive skill development for midwives.

\section{Background}

The role of the midwife is distinctive, multidimensional and complex, requiring highly developed clinical and cognitive skills. Midwives require well developed critical thinking skills to inform professional judgement that is evidence based, safe, woman-centred and individualised (Mènage, 2016; Jefford, et al., 2011). Critical thinking, a human cognitive process entailing focused thinking that is self-regulated and promotes development of knowledge to informing clinical judgement and decision making (Facione and Facione, 1996). There is a dearth of literature examining thinking processes undertaken within midwifery practice. In addition, strategies to promote development of critical thinking are often not clearly articulated, and routine measurement is rare (Carter et al., 2015; 2017c).

A Delphi study undertaken by Scheffer and Rubenfeld (2000) resulted in a distinct definition of critical thinking within nursing practice. A set of 17 critical thinking skills and habits of the mind in nursing were developed. Currently there is no discipline specific definition of critical thinking in midwifery practice. What is common to definitions from all disciplines, is the concept that critical thinking is a process to inform judgements and decision making.

Critical thinking is considered the 'cognitive engine' driving professional judgement and competent decision making (Facione and Facione, 1996). Effective problem solving is not possible without the application of critical thinking to the nature of a problem and possible solutions (Paul et al., 1995). The development of critical thinking is especially important in 
healthcare disciplines where clinical decisions are made continuously and sound judgement is crucial in the provision of safe and effective care.

\section{Critical Thinking in Midwifery}

Within most health disciplines, decisions are made using data obtained from history-taking, assessment, diagnostic testing and clinical cues during illness or injury. Using an analytical or rational approach, this clinical information combined with the evidence, is often used to inform decision making. In contrast to other health disciplines, midwifery care is philosophically grounded within a primary healthcare model where pregnancy and birth are

viewed as normal, physiological life events (International Confederation of Midwives [ICM], 2014; Jefford et al., 2011). Holistic decision making is required which incorporates diverse ways of knowing whilst valuing the significance of birth and becoming a mother (Siddiqui, 2005). Holistic, individualised care involves thinking critically about each woman and her unique situation, and modifying the approach to care to be congruent with the woman's response or preferences (Gilkison et al., 2016).

Midwifery care involves the development and establishment of a relationship with the woman which is grounded in a partnership. The woman-midwife partnership is reciprocal and based on equity, respect, trust, negotiation, and mutuality (Pairman and McAra-Couper, 2015), where shared decision making is promoted. Shared decision making acknowledges and values the own woman's knowledge of her body and facilitates her own decision making, supporting the ethical principle of autonomy. Within this model the woman's values and preferences are balanced with unbiased information based on the best available evidence (Freeman and Griew, 2007; Noseworthy at al., 2013).

To facilitate the provision of safe appropriate care, clinical judgements and decisions need to be based on appropriate evidence. Although there is a proliferation of evidence and clinical guidelines within maternity care, seeking the best available evidence is challenging. Contextual evidence that is congruent with the woman's individual circumstances is often absent. Although clinical guidelines espouse to provide best practice 'recipes' for care, not all are founded on valid and reliable evidence, and are often outdated (Prusova et al., 2014). Therefore, an essential skill in critical thinking in midwifery is the critical appraisal of literature to facilitate contextualised, evidence-based decision making. 
Sound professional judgment that is informed by critical thinking requires disciplined inquiry complemented by reflection (Paul et al., 1993). The cognitive ability to think critically and reflect involve similar intellectual processes where profound thought occurs resulting in practice evaluation. Reflection on clinical practice develops critical thinking competence by fostering introspection and identification of improvements to practice (Naber and Wyatt, 2014; Craft, 2005; Kennison, 2006; Bass et al., 2017). Self-awareness is a key factor that informs clinical midwifery judgement decision, facilitating reflection on the skills and knowledge the midwife brings to each situation and identifying alternate care options (Mènage, 2016).

Midwifery care is unique and complex, where decisions cannot be reasoned from the simple application of knowledge (Gilkison et al., 2016). A high level of cognitive skill is required to balance the philosophical underpinnings of midwifery care and its holistic nature, whilst applying contextualised evidence and honouring the woman's own preferences and choices. Considering the significance of critical thinking skills in midwifery practice, and the emphasis on development by professional regulatory bodies (Nursing and Midwifery Board of Australia [NMBA], 2010; Nursing and Midwifery Council, 2015), it is important that this skill is well defined, articulated, understood and measured. Measurement tools and conceptual models need to encompass the distinctive application of critical thinking to midwifery practice and provide explicit examples these so it is meaningful and purposeful, promoting reflection and discourse about this vital skill.

\section{Critical Thinking Development and Measurement in Midwifery}

Although critical thinking is well recognised as an essential skill for midwifery practice, literature related to critical thinking development and measurement is relatively scarce. Following an extensive search of the literature, only nine studies were found that involved midwifery students. Four studies analysed the effect of simulation on critical thinking development (Cioffi et al., 2005; Scholes et al., 2012; Lendahls and Oscarsson, 2017; Amod and Brysiewicz, 2017). Contradictory results were found between the studies, with three reporting an increase in critical thinking following the intervention (Cioffi et al., 2005; Lendahls and Oscarsson, 2017; Amod and Brysiewicz, 2017) and one study finding poor application of critical thinking to the simulation scenarios (Scholes et al., 2012). These results 
may reflect differences in how students were prepared for the activity, complexities of the simulation, and how critical thinking was measured. None of the tools used to measure critical thinking were tested for reliability and validity. For two of the studies that reported positive results (Lendahls and Oscarsson, 2017; Amod and Brysiewicz, 2017), there was no explicit evidence of critical thinking within the survey tool used, student quotes, or examples provided. The basis/evidence for this conclusion was unclear. These results also highlight the need for greater discourse on critical thinking in midwifery and objective measurement.

Two further studies explored the impact of innovative teaching strategies on critical thinking, including storytelling (Hunter and Hunter, 2006), and root cause analysis of a critical incident (Carter et al, 2014). These authors used a survey to collect data, however no psychometric testing of the tools were undertaken. Both studies reported positive effects of the teaching intervention, however only students' perceptions of increases were measured with no objective measure of baseline critical thinking levels and change.

The effect of a new curriculum on critical thinking skills included the implementation of an enquiry based curriculum (Snow and Torney, 2015), and a narrative centred curriculum (Gilkison et al., 2016). Both studies reported increases in critical thinking. Snow and Torney, (2015) used a survey to elicit student responses, however no information was provided on the survey items and it was unclear how critical thinking was measured. Details related to development, validity and reliability of the survey tool were not reported. Alternatively, Gilkison et al. (2016), used a participatory hermeneutic design, collecting data from lecturers' conversations during the research, focus groups with students and written reflections. Although critical thinking skills were perceived to increase as evidenced in the narratives, the authors did not evaluate whether the perceived increase in critical thinking skills translated to students' clinical practice. The results support the need for robust, reliable and valid measurement tools that can assess the effect of teaching strategies on critical thinking abilities and practice.

Another study explored cognitive skill development, including critical thinking, of students enrolled in an undergraduate midwifery program. Using focus groups and analysis of curriculum documents the authors identified an absence of explicit focus on cognitive skill development. Students perceived that cognitive skills would develop automatically through 
exposure to clinical practice and reported that academic assessments tended to focus on clinical skills and knowledge rather than the development of clinical judgement and critical thinking (Lake and Mclnnes, 2012). These results reinforced the need to explicitly articulate examples of critical thinking in midwifery throughout the curriculum and emphasise the ways to apply critical thinking skills to midwifery practice.

Of the limited studies available on critical thinking development, all reported students' perceptions of critical thinking with no objective measure of baseline levels and change. None of the tools were tested for reliability and validity. Some studies reported increases in critical thinking but it was unclear on what basis these conclusions were made, with little reference to critical thinking in survey questions or students' responses. Within the published studies reviewed, critical thinking in midwifery practice was loosely defined and poorly operationalised. Measurement tools were required to quantify the development of critical thinking and a provide a greater understanding of the concepts and elements involved in applying critical thinking to midwifery practice was needed.

\section{Overview of the research program}

A program of research was undertaken as part of the first author's doctoral program, the results of which were presented as a series of published papers. This body of work focussed on the evaluation and measurement of midwifery students' critical thinking skills in preparation for transition to a registered practitioner. The methodology utilised was a sequential mixed methods design. This methodology involved utilising the data and findings from each sequential study to drive the foundation and direction of the next. The aims of the work included:

1. Evaluate existing measurement tools used to assess critical thinking development.

2. Evaluate the effectiveness of teaching methodologies utilised to cultivate critical thinking abilities.

3. Develop and test three new tools created to assess the application of critical thinking to midwifery practice in undergraduate midwifery students.

4. Establish concurrent validity of the three new tools.

Initially, a systematic review of the literature was undertaken to evaluate tools used to 
measure critical thinking in undergraduate nursing and midwifery students. This review found no existing studies focussing on the development and measurement of the critical thinking skills that inform midwifery decision making and no available tools (Carter et al., 2015). Findings of this review suggested that commercially available critical thinking measurement tools are unlikely to be suitable for measurement of critical thinking in midwifery, and incongruous with measuring this skill in midwifery practice.

A further systematic review of the literature examined the effectiveness of teaching methodologies used to improve critical thinking in nursing and midwifery undergraduate education (Carter et al., 2016a). Findings from this review also confirmed the lack of measures to assess the efficacy of critical thinking teaching strategies in midwifery education and the absence of tools that measured critical thinking in midwifery practice. Findings of both of the reviews highlighted the need to develop distinct tools that assess the application of critical thinking to midwifery practice. Considering the complex nature of care and decision making in midwifery practice that is informed by critical thinking, a multimethod mode of measurement of students' critical thinking abilities was necessary.

Building on the conclusions of the two literature reviews a decision was made to develop, pilot and psychometrically test three tools specifically developed to assess the ability of undergraduate midwifery students to apply critical thinking to their practice. The tools were designed to focus on the application of student's critical thinking in midwifery practice as assessed by (1) preceptor, (2) student self-assessment, and (3) assessment of students' reflective writing on midwifery practice by faculty. Items within the three tools aimed to depict the complex and distinct qualities of critical thinking in midwifery practice. The development of multiple tools was also seen as a strategy to facilitate feedback to students from a variety of sources and promote objective assessment.

The three tools were called the Carter Assessment of Critical Thinking in Midwifery (CACTiM) - (1) Preceptor/Mentor, (2) Student and (3) Reflection versions. For each tool, an eight stage development process as recommended by DeVellis (2017) was employed. Draft items were initially developed from a comprehensive examination of the literature to ascertain potential item content and determine appropriate conceptual domains. As there were no identified tools measuring critical thinking in midwifery, tools that measured critical thinking in nursing 
were identified. These tools were reviewed, however, most items were centred around identification of a change in a patient's symptoms and condition and the instigation of nursing interventions. The items included in the National Competency Standards for the Midwife (ANMC, 2006) were also examined. We then created items that incorporated the principles of critical thinking but also integrated midwifery philosophy and practice that represents woman centred care, the relational partnership between and woman and midwife and focussed on the provision of informed choice (ICM, 2014; Renfrew et al., 2014).

To ensure conceptual congruence was present between the draft items and the characteristics of critical thinking, the items for each of the three tools were firstly reviewed by a panel of expert midwifery lecturers and clinicians. The items were then mapped against the 17 skills and habits of the mind contained in the nursing definition of critical thinking (Scheffer and Rubenfeld, 2000).

The three tools were piloted with different samples (including preceptors and students). Psychometric testing confirmed the reliability and validity of the tools in measuring critical thinking skills in midwifery practice (Carter et al., 2016b, Carter et al., 2017a, Carter et al., 2017b). Further testing of matched responses for participating students on the three tools also indicated good reliability and concurrent validity (Carter et al., 2017c). Examination of correlations between the three tools found positive relationships with students' prior qualifications, academic performance and progression through the program (Carter et al., 2017c).

\section{Development of a Conceptual Model of Critical Thinking in Midwifery Practice}

Elements and concepts that shape critical thinking in midwifery practice emerged from (1) the review of literature on critical thinking and midwifery, (2) reviews evaluating current available tools, (3) development of survey items and expert review of these, and (4) testing of the three tools. These processes informed the development of a conceptual model for critical thinking in midwifery practice. This model presents a new understanding of critical thinking in midwifery practice.

Insert Figure 1 about here 


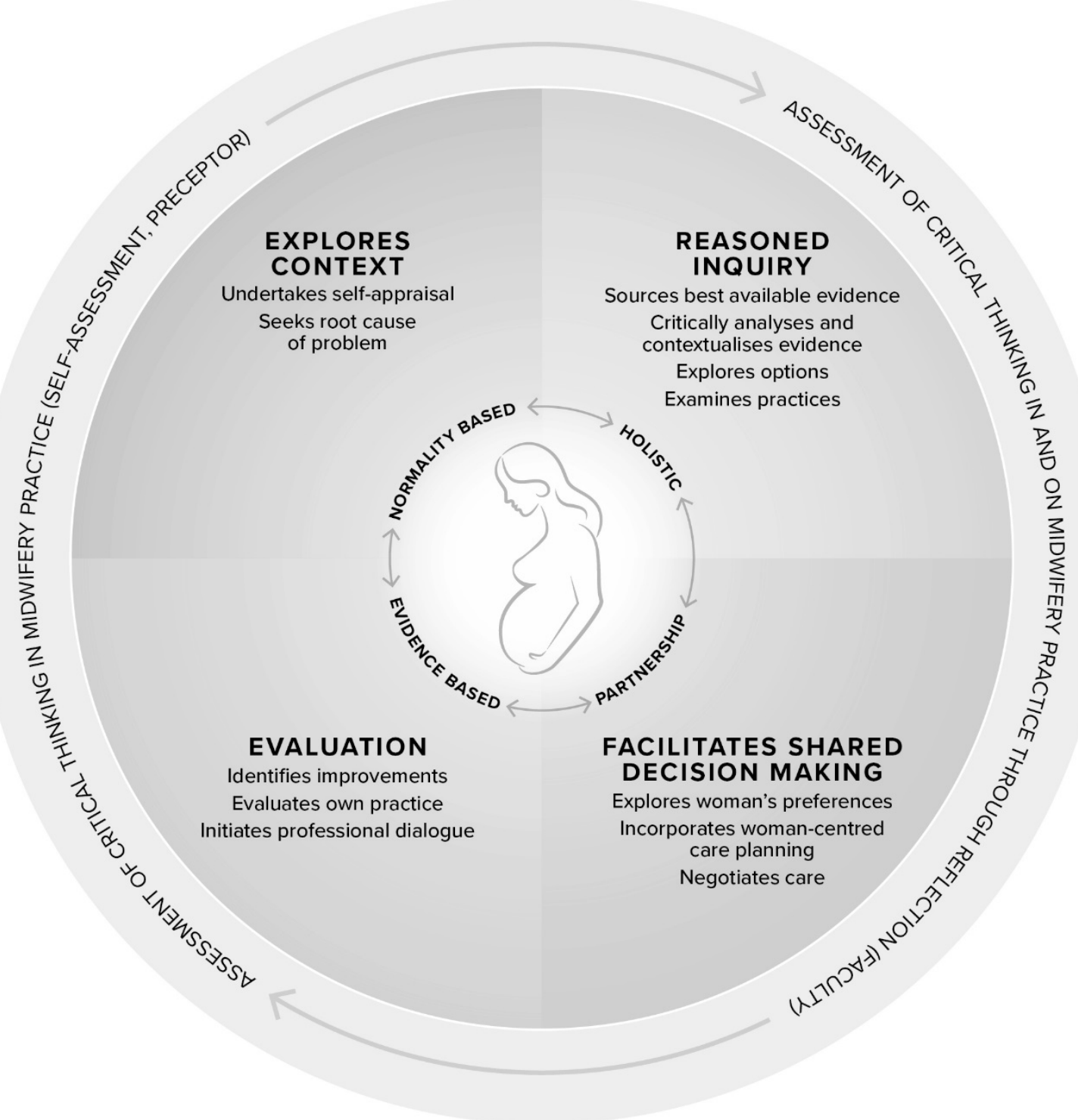

\section{Conceptual model of critical thinking in midwifery practice}

The conceptual model of critical thinking in midwifery practice is embedded within a womancentred philosophy of care. Woman centred care focusses on the individual woman's needs, preferences and expectations as opposed to a focus on the needs of the organisation or caregiver, acknowledging the woman's autonomy in decision making, informed choice and sovereignty (NMBA, 2010). Foundations of the overarching philosophical framework that support this conceptual model of critical thinking in midwifery practice are:

- Pregnancy and birth are normal physiological events; 
- Midwifery care and decision making are based on high quality evidence;

- Midwifery care involves a relationship between the woman and midwife based on partnership, equal power and mutual respect; and

- Midwifery care is holistic and individualised.

This conceptual model involves four phases and twelve elements. These phases and elements were developed from the items and factors identified within the three CACTiM tools. The phases within this conceptual model are fluid and not restricted by sequencing in any particular order.

\section{Phase 1: Explores Context}

This phase involves the gathering of information to analyse the individual context, hence cultivating critical thinking through consideration of the whole clinical picture. The process of surveying beneath the surface and identifying factors that influence the situation are recognised as a key factor in critical thinking (Thompson and Thompson, 2008). Consideration of the contextual perspective is established as one of the core 'habits of mind' within the statement of critical thinking in nursing (Scheffer and Rubenfeld, 2000).

\section{- Undertakes self-appraisal}

This element involves identification of any gaps and skills related to the clinical situation. It also involves reflection by the midwife or student on their values and beliefs and consideration of the impact of these on care provided. This self-evaluation may lead to consideration of a different approach to care or consultation and referral to access additional expertise. This ability to undertake self-appraisal and change practice or behaviours demonstrates two of the core components of 'habits of mind' of reflection and flexibility in thinking within the statement of critical thinking in nursing (Scheffer and Rubenfeld, 2000). Within the element of self-appraisal the need to undertake professional development or further learning to address any identified gaps in practice may be prompted.

\section{- Seeks root cause of a problem}

This element involves deeper cognitive thinking and rather than simply responding to current cues or problems, aims to seek and address the cause. Recognition of the significance of the 
clinical situation is also an important step in this element. The skills of interpretation, involving comprehension of the meaning, or significance of a situation or problem is a fundamental cognitive skill in critical thinking (Facione, 1990). Seeking a root cause for a problem or situation utilises well developed critical thinking skills and is recognised in the analysis phase of the critical thinking in nursing definition (Scheffer and Rubenfeld, 2000). Failing to identify the root cause of the clinical situation or problem and the significance of the scenario can negatively impact the quality and safety of midwifery care.

In our earlier work, we piloted and tested an innovative teaching and learning strategy where students performed root cause analysis on previous coroner's cases (Carter et al, 2014). This study identified that the process of undertaking root cause analysis contributed to the development of critical thinking skills and was evaluated positively by students and industry midwifery partners.

\section{Phase 2: Reasoned Inquiry}

The phase of reasoned inquiry involves examination of the appropriateness of clinical procedures and care, exploration of information and evidence to inform future practice. Reasoning involves the analysis of evidence and construction of decisions (Cottrell, 2011), and inquiry encourages a depth of exploration and discovery instead of using decision making based on rote learning of facts or rules. Exploration and discovery are essential elements in critical thinking (Facione, 1990), and essential in the provision of quality midwifery care (Jefford, 2014).

\section{- Sources best available evidence}

Reasoned inquiry may include a search of the literature, prioritising high level evidence and/or seeking relevant clinical guidelines or policies. Seeking information is recognised as a core skill within the critical thinking in nursing definition (Scheffer and Rubenfeld, 2000). Woman centred and quality midwifery practice is exemplified by the application of best available evidence, integrated with the woman's own preferences, needs and choices and the application of sound clinical decision making utilising highly developed critical thinking skills (Fullerton and Thompson, 2005).

\section{- Critically analyses and contextualises evidence}


This element involves consideration of the evidence pertaining to a woman's individual situation, incorporating her preferences. It also involves contextualising evidence and/or policies to determine their appropriate application or variances required. As discussed earlier, the application of evidence to midwifery decision making is complex. Critical appraisal of the literature to ensure the best available quality evidence is utilised to inform decision making is vital. The evidence then needs to be contextualised to the woman's own unique circumstances as well as consideration of her preferences, needs and choices, to ensure decisions related to care are relevant and woman centred (Ménage, 2016). Therefore, an essential skill in critical thinking in midwifery is the critical appraisal of literature to facilitate contextualised, evidence-based decision making. Querying evidence is recognised as a core skill of critical thinking (Facione, 1990).

\section{- Explores options}

Critical thinking involves the exploration of multiple options and alternatives to a given situation. Facione (1990) refers to this critical thinking process as conjecturing alternatives where multiple alternatives for solving a problems are considered. This exploration may involve the use of intuition and/or previous experiences through identification and clustering of a variety of cues using pattern recognition Incorporation of intuition within midwifery practice has been recognised as a way to gain knowledge and guide decision making (Muoni, 2012). Decision making informed by intuition utilises pattern recognition based on prior experiences (Steinhauer, 2015). Using the knowledge gained from past experiences to inform clinical judgement is a key factor in the application of critical thinking (Facione and Facione, 1996).

\section{- Examines practices}

This element encourages further inquiry and examination of observed practices to determine if they are evidence based and/or woman centred. This includes recognition of unnecessary interventions or institutional 'unwritten rules' that do not optimise woman-centred care. 'Unwritten rules' are ritualistic practices that are not based on the principles of evidence based practice instead they are grounded in tradition (Hunter, 2005). If left unrecognised and addressed unwritten rules can promptly be embedded within the cultural norm of the health facility (Hunter, 2005) and are often unquestioningly accepted by midwives (Cluett and Bluff, 
2006). The questioning of 'unwritten rules', and practice using a woman-centred and evidence-based critical lens are vital cognitive processes in midwifery.

\section{Phase 3: Facilitates Shared Decision Making}

This phase includes aspects of critical thinking unique to the midwifery profession and relates to the exploration and sharing of literature, policies and guidelines and alternatives with women to facilitate informed choice. Also entailed in this phase is negotiation and collaboration with other healthcare providers, respecting and honouring the woman's choices. Provision of appropriate and evidence based information to facilitate women's informed choice and decision making is central to midwifery care provision (ICM, 2014; Brady et al., 2016) and is an essential process within midwifery critical thinking and clinical decision making.

\section{- Explores woman's preferences}

Congruent with a woman-centred approach to care, this element may involve a general discussion regarding the woman's preferences for care or a more specific conversation related to the current episode/event in practice. This exploration of women's preferences acknowledges that women's autonomy is a central element to informed decision making.

\section{- Incorporates woman-centred care planning}

This element entails care planning being centred around the woman and incorporation of her preferences and needs. It also involves individualising the sequencing of care, the nature of care provided, and sharing and discussing contextualised evidence and information with the woman. These actions foster the woman's autonomy through the provision of high quality evidence and advice thereby enhancing the informed decision making (ICM, 2014). Ensuring the woman's own knowledge, experiences and desires are incorporated into care planning making midwifery decision multifaceted making more complex requiring well developed critical thinking skills.

\section{- Negotiates care}

This element of critical thinking in midwifery practice acknowledges that midwifery care is provided within a collaborative milieu incorporating all disciplines involved in the care, 
centred around the woman and her family. Developing collaborative relationships within the multidisciplinary team ensures the woman receives the most appropriate care for her needs. Advocating for the woman's choices or negotiating appropriate evidence based care is an essential midwifery capability that optimises outcomes for women and their babies (ANMC, 2006; Skinner and Foureur, 2010). Sound collaborative practice and engaging in critical conversations about care avoids tension caused by differing opinions which affect crucial clinical judgements (Watson et al., 2012; Van Helmond et al., 2015).

\section{Phase 4: Evaluation}

Evaluation is a critical component of quality care and practice improvements. This evaluative phase incorporates the ability of the midwife/student to identify quality improvements required within the organisation, assess and reflect on the quality of care provided, seek feedback from others and work in collaboration to constantly improve practice. Evaluation of care including self-evaluation, service evaluation and care provision supports safe and effective midwifery practice, promoting critical reflection and thinking, informing professional judgements (Gilkison et al., 2016; Ménage, 2016).

\section{- Identifies improvements}

This step in critical thinking involves being proactive and addressing any deficits in policies/guidelines, practices or the environment that hinder care. The identification of quality improvements within the practice environment and refinement of existing systems is a essential to promote safe midwifery practice and a central element of critical thinking (Cronenwett et al., 2007). This element involves greater depth of critical thinking as it is not only concerned with the present situation but considers improvements for care in the future.

\section{- Evaluates own practice}

Self-reflection and consideration following the event on the care provided and outcomes is characteristic of this element. It also involves seeking feedback from others, including the woman, preceptor or others involved in the care. This reflection may identify particular aspects of the midwife's or student's practice or care that could be improved.

Reflection and critical thinking are essential components of safe midwifery practice. The 
clinical setting provides a rich milieu for reflection which in turn enhances development of critical thinking (Kennison, 2006). This type reflection on practice further develops critical thinking abilities through self-evaluation of intellectual thought and practice, and planning changes and practice enhancements (Rubenfeld and Scheffer, 2015). Reflection on midwifery practice ensures that practice is based within a holistic, women centred philosophy and is consistent with midwifery values. Undertaking self-evaluation through reflection and incorporation of feedback from others results in analysis of self, intellectual thought and practice patterns, facilitating critical thinking and transformational practice (Rubenfeld and Scheffer, 2015). Reflection is one of the ten recognised 'habits of mind' within the critical thinking in nursing definition (Scheffer and Rubenfeld, 2000).

\section{- Initiates professional dialogue}

Professional midwifery dialogue within this element is focussed on evaluation of practice and may involve discussion with other colleagues around clinical care to generate new knowledge (this may occur prior, during or following the event). Alternatively, this dialogue may involve specific debriefing related to involvement in a complex situation. A culture of support and/or debriefing following a complex situation assists midwifery students to articulate their learning needs and develop resilience fostering reflection to process experiences in future practice (Davies and Coldridge, 2015). A further purpose of this debriefing discussion involves a process of 'unpacking' the clinical situation and learning from the incident. The initiation and implementation of professional dialogue promotes a critical approach to practice, where practitioners vocalise their thinking, ask questions and provide justification for decisions or actions. Professional dialogue makes explicit the critical thinking utilised in making professional judgements (Collington and Hunt, 2006).

\section{Application of the Model in Research, Education and Practice}

\section{Research}

The conceptual model of critical thinking in midwifery practice was derived from an extensive program of research to inform its' development, however further research is required. The program of work underpinning the conceptual model produced three tools that were found to valid and reliable measurements of critical thinking in midwifery practice, however the elements of the model have not been individually tested to ensure they incorporate all 
aspects of critical thinking in midwifery. This testing could also identify which elements of the model are considered most important and well developed in midwifery students or midwives. Testing the model could also identify any elements that are difficult to understand or apply. When the model was developed it was considered to be a fluid model and the phases and elements were not ordered in sequence or priority. Testing of the model would further explore this concept of fluidity of the model.

Despite the importance of critical thinking, relatively few previous studies have aimed to investigate critical thinking development. Longitudinal cohort studies could shed light on the development of critical thinking in midwifery student practice.

Many previous studies have focussed on students' perceptions of critical thinking with no objective measure of baseline levels and change (Snow and Torney, 2015; Hunter and Hunter, 2006; Carter et al, 2014). The conceptual model provides a basis for critical thinking in midwifery practice that is currently missing in the literature. Similar to previous work, a Delphi study of midwifery practitioners and educators could use the model as an instrument to collaborate on the development of a consensus definition for critical thinking in midwifery.

\section{Education}

The conceptual model aims to provide a working model and definition of critical thinking in midwifery practice. Elements of the model aim to operationalise critical thinking in midwifery practice to enhance student learning and provide a guide for clinical preceptors and educators. The model can be easily adapted to both theoretical and clinical aspects of curricula.

Midwifery programs could incorporate the CACTiM self-assessment and reflective writing tools on a regular basis and provide explicit feedback to students. Furthermore, the model provides clinical preceptors with explicit examples of critical thinking in midwifery practice and enhances their ability to provide feedback to students and reflect on their own critical thinking abilities.

The new model provides a framework to guide curriculum design and teaching methodologies in the development of critical thinking abilities. The phases and elements within the model 
can be used as a structure to ensure that the facets of critical thinking in midwifery practice are adequately addressed within undergraduate midwifery programs and individual courses.

\section{Clinical Practice}

The ultimate goal of the conceptual model is to improve midwifery practice. The conceptual model aims to provide a guide for students in their transition to registered practice and provides a solid foundation for ongoing professional competence. The conceptual model and the three measurement tools are all grounded in clinical practice and are easily applied. Although the tools and model were originally designed for use with midwifery students they could also inform experiences midwives' practice.

\section{Measurement and Assessment}

To encompass the distinct and multifaceted features of critical thinking in midwifery practice the use a multi-method system of measurement is required. This approach facilitates feedback to midwives or students from a variety of sources and provides holistic real-world assessment on the application of critical thinking skills in practice. Feedback on a midwife's or student's capability to utilise critical thinking in midwifery practice is facilitated through self-assessment (by the student) and the midwife's / student's preceptor/mentor. Evaluation of the application of critical thinking on and in midwifery practice is enabled through faculty assessment of reflective writing on practice.

\section{Conclusion}

The use of sophisticated critical thinking skills to inform clinical judgements and decisions in midwifery practice is essential in the provision of woman centred, best practice and safe midwifery care. Yet, few studies have explored or measured the cognitive skill of critical thinking in midwifery practice. In the few studies available, critical thinking was loosely defined and poorly operationalised.

Three new instruments that measure critical thinking in midwifery practice are now freely available and easily applied in both clinical practice and the classroom. The tools provide another dimension in the assessment of clinical practice that incorporates the application of cognitive skills, as well as clinical skill development. 
The development of a conceptual model for critical thinking in midwifery practice provides new understanding of this important cognitive skill and application to practice. This understanding can promote critical thinking development and assist midwives to navigate and inform complex decision making in midwifery. Further testing of the elements and concepts of this model is recommended to ensure they are fully representative of the complex thought processes involved in midwifery practice. It is envisaged that the conceptual model of Critical Thinking in Midwifery Practice will promote discourse about this important cognitive skill and provide midwifery clinicians, educators and students with explicit examples and concepts of critical thinking in midwifery practice. 


\section{References}

Amod, H.B., Brysiewicz, P., 2017. Developing, implementing and evaluating a simulation learning package on post-partum haemorrhage for undergraduate midwifery students in KwaZulu-Natal. Health SA Gesondheid 22, 194-201. https://doi.org/10.1016/i.hsag.2016.11.004

Australian College of Midwives, 2011. Philosophy of the Midwife. http://www.midwives.org.au/scripts/cgiip.exe/Wservice=MIDW/ccms.r?pageid=100 19

Australian Nursing and Midwifery Council, 2006. National Competency Standards for the Midwife. Retrieved from http://www.nursingmidwiferyboard.gov.au/CodesGuidelines-Statements/Codes-Guidelines.aspx\#competencystandards.

Bass, J., Fenwick, J., Sidebotham, M., 2017. Development of a model of holistic reflection to facilitate transformative learning in student midwives. Women and Birth. 30 (3), 227235. http://dx.doi.org/10.1016/j.wombi.2017.02.010.

Brady, S., Bogossian, F., Gibbons, K., 2016. Development and piloting the Woman Centred Care Scale (WCCS), Women and Birth, http:// dx.doi.org/10.1016/j.wombi.2016.10.010.

Carter, A.G., Sidebotham, M., Creedy, D.K., Fenwick, J., Gamble, J., 2014. Using root cause analysis to promote critical thinking in final year Bachelor of Midwifery students. Nurse Education Today 34, 1018-1023. https://doi.org/10.1016/j.nedt.2013.10.020

Carter, A.G., Creedy, D.K., Sidebotham, M., 2015. Evaluation of tools used to measure critical thinking development in nursing and midwifery undergraduate students: $A$ systematic review. Nurse Education Today 35, 864-874. https://doi.org/10.1016/j.nedt.2015.02.023

Carter, A. G., Creedy, D. K., \& Sidebotham, M. 2016a. Efficacy of teaching methods used to develop critical thinking in nursing and midwifery undergraduate students: A systematic review of the literature. Nurse Education Today, 209-218. https://dx.doi.org/10.1016/j.nedt.2016.03.010

Carter, A.G., Creedy, D.K., Sidebotham, M., 2016b. Development and psychometric testing of the Carter Assessment of Critical Thinking in Midwifery (Preceptor/Mentor version). Midwifery 34, 141-149. https://doi.org/10.1016/j.midw.2015.12.002

Carter, A.G., Creedy, D.K., Sidebotham, M., 2017a. Critical thinking skills in midwifery practice: Development of a self-assessment tool for students. Midwifery 50, 184192. https://doi.org/10.1016/j.midw.2017.04.010

Carter, A.G., Creedy, D.K., Sidebotham, M., 2017b. Critical thinking evaluation in reflective writing: Development and testing of Carter Assessment of Critical Thinking in 
Midwifery (Reflection). Midwifery 54, 73-80.

https://doi.org/10.1016/j.midw.2017.08.003

Carter, A., Creedy, D.K., Sidebotham, M. 2017c. Measuring critical thinking in pre-registration midwifery students: A multi-method approach. Manuscript submitted for publication to Nurse Education Today, August 2017.

Cioffi, J., Purcal, N., Arundell, F., 2005. A pilot study to investigate the effect of a simulation strategy on the clinical decision making of midwifery students. The Journal of Nursing Education 44, 131-134.

Cluett, E., Bluff, R., 2006. From practice to research. In: Cluett, E., Bluff, R., (Eds.), Principles of Practice and Research in Midwifery $2^{\text {nd }}$ edn. Churchill Livingstone Elsevier, New York, 13-29.

Collington, V., Hunt, S. C., 2006. Reflection in midwifery education and practice: an exploratory analysis. Evidence Based Midwifery, 4(3), pp. 76-82.

Cottrell, S., 2011. Critical Thinking Skills: Developing Effective Analysis and Argument. Palgrave Macmillan, Hampshire.

Craft, M., 2005. Reflective writing and nursing education. The Journal of nursing education 44, 53-57.

Cronenwett, L., Sherwood, G., Barnsteiner, J., et al., 2007. Quality and safety education for nurses. Nursing Outlook 55, 122-131.

Davies, S., Coldridge, L., 2015. 'No Man's Land': An exploration of the traumatic experiences of student midwives in practice. Midwifery 31, 858-864.

DeVellis, R. F., 2017. Scale Development: Theory and Applications, fourth ed. Thousand Oaks, California, Sage.

Facione, P.A., 1990. Critical Thinking: A Statement of Expert Consensus for Purposes of Educational Assessment and Instruction, Executive Summary: "The Delphi Report". The Californian Academic Press, CA. Retrieved from http://assessment.aas.duke.edu/documents/Delphi_Report.pdf

Facione, N.C., Facione, P.A., 1996. Externalizing the critical thinking in knowledge development and clinical judgment. Nurs Outlook 44, 129-136. https://doi.org/10.1016/S0029-6554(06)80005-9

Freeman, L.M., Griew, K., 2007. Enhancing the midwife-woman relationship through shared decision making and clinical guidelines. Women Birth 20, 11-15. https://doi.org/10.1016/j.wombi.2006.10.003

Gilkison, A., Giddings, L., Smythe, L., 2016. Real life narratives enhance learning about the 'art and science' of midwifery practice. Adv Health Sci Educ Theory Pract 21, 19-32. 


\section{https://doi.org/10.1007/s10459-015-9607-z}

Hunter, B., 2005. Emotion work and boundary maintenance in hospital-based midwifery. Midwifery 21, 253-266.

Hunter, L.P., Hunter, L.A., 2006. Storytelling as an educational strategy for midwifery students. Journal of Midwifery \& Women's Health 51, 273-278. https://doi.org/10.1016/j.jmwh.2005.12.004

International Confederation of Midwives, 2014. Philosophy and model of midwifery care. The Hague. Retrieved from http://www.internationalmidwives.org/assets/ uploads/documents/CoreDocuments/CD2005_001\%20V2014\%20ENG \%20Philosophy\%20and\%20model\%20of\%20midwifery\%20care.pdf.

Jefford, E., 2014. Midwives' decision-making in 2nd stage labour-report on an interpretive study. Australian Nursing and Midwifery Journal 21, 41-2.

Jefford, E., Fahy, K., Sundin, D., 2011. Decision-making theories and their usefulness to the midwifery profession both in terms of midwifery practice and the education of midwives. Int J Nurs Pract 17, 246-253. https://doi.org/10.1111/j.1440$172 X .2010 .01900 . x$

Kennison, M.M., 2006. The evaluation of students' reflective writing for evidence of critical thinking. Nurs Educ Perspect 27, 269-273.

Lake, S., McInnes, R.J., 2012. Exploring cognitive skill development in midwifery education. Nurse Education in Practice 12, 264-268. https://doi.org/10.1016/j.nepr.2012.04.015

Lendahls, L., Oscarsson, M.G., 2017. Midwifery students' experiences of simulation- and skills training. Nurse Education Today 50, 12-16. https://doi.org/10.1016/j.nedt.2016.12.005

Ménage, D., 2016. Part 2: A model for evidence-based decision-making in midwifery care. British Journal of Midwifery 24, 137-143. https://doi.org/10.12968/bjom.2016.24.2.137

Muoni, T., 2012. Decision-making, intuition, and the midwife: Understanding heuristics. British Journal of Midwifery 20 (1), 52-56.

Naber, J., Wyatt, T.H., 2014. The effect of reflective writing interventions on the critical thinking skills and dispositions of baccalaureate nursing students. Nurse Education Today 34, 67-72. https://doi.org/10.3928/01484834-20140806-06

Noseworthy, D.A., Phibbs, S.R., Benn, C.A., 2013. Towards a relational model of decisionmaking in midwifery care. Midwifery 29, e42-48. https://doi.org/10.1016/j.midw.2012.06.022

Nursing and Midwifery Board of Australia, 2010. National Competency Standards for the 
Midwife. Retrieved from http://www.nursingmidwiferyboard.gov.au/CodesGuidelines-Statements/Professional-standards.aspx.

Nursing and Midwifery Council, 2015. The Code: Professional Standards of Practice and Behaviour for Nurses and Midwives (Melbourne). Retrieved from (https://www.nmc.org.uk/globalassets/sitedocuments/nmc-publications/nmccode.pdf).

Pairman, S., McAra-Couper, J., 2015. Theoretical frameworks for midwifery practice In S. Pairman, S. K., Tracy, C. Thorogood, J. Pincombe (Eds), Midwifery: Preparation for practice, (3rd ed), (pp 383-411). Chatswood, NSW, Churchill Livingstone.

Paul, R., Binker, A.J.A., Willsen, J., 1995. Critical thinking: how to prepare students for a rapidly changing world. Santa Rosa, California, Foundation for Critical Thinking.

Prusova, K., Churcher, L., Tyler, A., Lokugamage, A.U., 2014. Royal College of Obstetricians and Gynaecologists guidelines: how evidence-based are they? J Obstet Gynaecol 34, 706-711. https://doi.org/10.3109/01443615.2014.920794

Renfrew, M., McFadden, A., Bastos, M., et al., 2014. Midwifery and quality care: findings from a new evidence-informed framework for maternal and newborn care. The Lancet, http://dx.doi.org/10.1016/S0140-6736(14)60789-3.

Rubenfeld, M.G., Scheffer, B. 2015. Critical Thinking TACTICS for Nurses. Jones \& Bartlett, Boston, MA.

Scheffer, B.K., Rubenfeld, M.G., 2000. A consensus statement on critical thinking in nursing. The Journal of nursing education 39, 352-359.

Scholes, J., Endacott, R., Biro, M., Bulle, B., Cooper, S., Miles, M., Gilmour, C., Buykx, P., Kinsman, L., Boland, R., Jones, J., Zaidi, F., 2012. Clinical decision-making: midwifery students' recognition of, and response to, post partum haemorrhage in the simulation environment. BMC Pregnancy Childbirth 12, 19. https://doi.org/10.1186/1471-239312-19.

Siddiqui, J., 2005. The role of knowledge in midwifery decision making. In M.D. Raynor, J.E. Marshall, A. Sullivan, (Eds.), Decision making in midwifery practice. (pp. 23-36). London, Churchill Livingstone.

Steinhauer, S., 2015. Decision making in midwifery: rationality and intuition. The Practising Midwife 18, 14-18.

Skinner, J. P., Foureur, M., 2010. Consultation, referral, and collaboration between midwives and obstetricians: lessons from New Zealand. Journal of Midwifery and Women's Health 55, 29-37.

Snow, S., Torney, L., 2015. An evaluation of the first year of an enquiry-based learning midwifery curriculum. British Journal of Midwifery 23, 894-900. 


\section{https://doi.org/10.12968/bjom.2015.23.12.894}

Thompson, S., Thompson, N., 2008. The Critically Reflective Practitioner. Palgrave Macmillan, Basinstoke.

Van Helmond, I., Korstjens, I., Mesman, J., Nieuwenhuijze, M., Horstman, K., Scheepers, H., Spaanderman, M., Keulen, J., de Vries, R., 2015. What makes for good collaboration and communication in maternity care? A scoping study. International Journal of Childbirth 5, 210-223. https://doi.org/10.1891/2156-5287.5.4.210.

Watson, B.M., Heatley, M.L., Kruske, S.G., Gallois, C., 2012. An empirical investigation into beliefs about collaborative practice among maternity care providers. Australian Health Review 36, 470459. 